\title{
CONSIDERAÇÕES SOBRE PESQUISA E GÊNEROS DISCURSIVOS PARA A EDUCAÇÃO BÁSICA
}

\author{
Consideratrions about Consideraciones sobre \\ Research and Discourse Genres investigación y géneros discursivos \\ for Basic Education para la educación básica
}

\author{
Luiz Antônio Ribeiro* \\ Centro Federal de Educação Tecnológica de Minas Gerais (Cefet-MG), \\ Programa de Pós-Graduação em Estudos de Linguagens, Belo Horizonte, MG, Brasil \\ Cláudia Mara de Souza** \\ Centro Federal de Educação Tecnológica de Minas Gerais (Cefet-MG) \\ Departamento de Linguagem e Tecnologia (Deltec), Belo Horizonte, MG, Brasil
}

\begin{abstract}
Resumo: Este artigo visa a refletir sobre a necessidade de inserção de práticas de pesquisa e de gêneros discursivos atinentes à investigação científica tanto nas escolas de educação básica quanto nas instituições de ensino superior. O referencial teórico fundamenta-se, principalmente, nas abordagens bakhtiniana e swalesiana de gêneros discursivos, além de trabalhos e documentos sobre a inserção da pesquisa e do letramento em gêneros nos diferentes níveis de ensino. O corpus constitui-se de vinte e oito questionários repondidos por estudantes ingressantes no curso de Letras de uma instituição da rede federal de ensino sobre sua experiência com leitura e produção de gêneros aplicados à pesquisa e sobre as expectativas dessa vivência pedagógica para sua formação profissional. Os resultados sinalizam a carência de didáticas de ensino de gêneros acadêmicos e a necessidade de investimentos em pesquisa desde a educação básica até a graduação, como forma de criar uma cultura da pesquisa.
\end{abstract}

Palavras-chave: Pesquisa. Gênero acadêmico. Práticas de letramento.

\begin{abstract}
This paper aims to reflect over the need for insertion of research practices and discourse genres related to scientific research, both in primary and higher education schools. The theoretical framework was mainly the Bakhtinian and Swalesian approaches to discursive genres, in addition to works and documents about the insertion of research and literacy in genres at the different levels of education. The corpus consisted of twenty-eight questionnaires answered by students who are entering the Language and Litterature undergraduate course at a school in the federal education network regarding their experience with reading and producing genres applied to research, as well as the expectations of this pedagogical experience for their vocational training. The results signal a lack of didactics in order to teach academic genres and the need for investments in research from basic education to undergraduation, as a way to create a research culture.
\end{abstract}

Keywords: Research. Academic genre. Literacy practices.

\footnotetext{
* Doutor em Letras - Linguística e Língua Portuguesa pela PucMinas. Professor Permanente do Programa de Pós-Graduação em Estudos Linguísticos. ORCID: http://orcid.org/0000-0001-8912-9764. E-mail: luiz.antonio.ribeiro32@gmail.com

${ }^{* *}$ Doutora em Estudos Linguísticos pela UFMG. Professora do Departamento de Linguagem e Tecnologia - Deltec. ORCID: http://orcid.org/0000-0003-3383-9534. E-mail: claudiaitab@gmail.com
} 
Resumen: Este artículo tiene el objetivo de reflexionar sobre la necesidad de inserción de prácticas de investigación y de géneros discursivos relacionados con investigación científica en escuelas de educación básica y en las instituciones de enseñanza superior. El referencial teórico se basa principalmente en abordajes de Bajtín y Swales de géneros discursivos, allá más de trabajos y documentos sobre la inserción de investigación y de letramiento en géneros en los diferentes niveles de enseñanza. El corpus se constituye de veintiocho cuestionarios respondidos por estudiantes ingresantes en el curso de Letras de una institución de la red federal de enseñanza sobre su experiencia con lectura y producción de géneros utilizados en la investigación sobre las expectativas de esa vivencia pedagógica para formación profesional. Los resultados señalan ausencia de didácticas de enseñanza de géneros académicos y la necesidad de inversiones en investigación desde la educación básica hacia los cursos de grado, como manera de crear una cultura da investigación.

Palabras clave: Investigación. Género académico. Prácticas de letramiento.

\section{INTRODUÇÃO}

A pesquisa que originou este artigo insere-se no quadro teórico da Linguística Aplicada e tomou como reflexão principalmente as obras de Bakhtin (1997) e de Swales (1990; 2004), sem necessariamente limitar-se a elas. O artigo resulta de experiências vivenciadas pelos autores na educação superior, em especial no curso de Letras, a partir do trabalho com gêneros acadêmicos e da observação das dificuldades dos discentes em desenvolver atividades de leitura e produção textual relacionadas à pesquisa. Embora os documentos oficiais que norteiam a educação básica estimulem a atividade de pesquisa, esta parece ser quase inexistente ou ainda bastante incipiente nas práticas escolares. Tal realidade acaba por constituir um hiato entre as atividades de letramento na educação básica e aquelas propostas no ensino de graduação.

A consequência disso é que nem sempre os graduandos tomam consciência da necessidade de apropriação dos gêneros recorrentes na pesquisa para a criação de uma identidade com a comunidade de discurso ou ainda para sua formação profissional plena. Essa realidade evidencia a necessidade do ensino de gêneros acadêmico-científicos já na educação básica e a intensificação desse estudo na educação superior. As atividades de ensino desenvolvidas, obviamente, devem estar atreladas às práticas científicas, de pesquisa, em si. Isso nos motivou a investigar que experiências relativas aos gêneros discursivos acadêmicos os alunos ingressantes no ensino superior já trazem internalizadas.

Desde já, destacamos a importância de os graduandos participarem de práticas de letramento em gêneros acadêmicos, dado que essa iniciativa será a chave para a construção de novas formas de pensar, interagir e produzir conhecimentos de natureza científica, bem como para a criação de um vínculo identitário com a academia. Tais práticas oportunizam que os graduandos assumam novas posturas investigativas, bem como invistam em diferentes possibilidades de construir e expressar conhecimentos acadêmico-científicos. O professor terá maior êxito na mediação dos conhecimentos, caso conheça melhor tanto o nível de letramento em que os graduandos se encontram quanto suas expectativas em relação ao estudo de gêneros que efetivamente circulam nessa esfera de comunicação. 
Tendo em vista os objetivos propostos, este artigo apresenta a seguinte organização: primeiramente, refletimos sobre a noção de gêneros discursivos e de gêneros acadêmicos, tomando como base principalmente os estudos de Bakhtin (1997) e Swales (1990; 2004). Do primeiro, consideramos o caráter social, histórico e ideológico da linguagem e a definição de gênero (enunciado), cuja configuração se exprime por seu tema, seu estilo e sua composição. Do segundo, exploramos, entre outros aspectos, a aprendizagem e a aquisição de gêneros em contextos acadêmicos. Em seguida, refletimos sobre os gêneros acadêmico-científicos e a importância das práticas de letramento desde a educação básica, visto que isso favorecerá aos educandos o desenvolvimento do espírito investigativo e o raciocínio crítico, o domínio das habilidades de leitura e produção de gêneros acadêmicos, bem como a construção de uma identidade e de integração com esse ambiente.

$\mathrm{Na}$ seção seguinte, apresentamos o percurso metodológico adotado na pesquisa. Posteriormente descrevemos os dados da entrevista realizada com alunos iniciantes na graduação acerca de suas representações sobre o estudo dos gêneros acadêmicos e procuramos analisá-las à luz do referencial teórico apresentado. Nas considerações finais, destacamos os aspectos principais da pesquisa realizada e enfatizamos a necessidade da integração entre ensino e pesquisa nas escolas, com vistas à elevação da qualidade do nível de ensino e à formação de cidadãos críticos, profissionalmente qualificados e capazes de propor soluções para os problemas emergentes em nossa sociedade. Esse encaminhamento levou em conta a observação e a compreensão dos dados a partir dos resultados obtidos.

\section{GÊNEROS DE DISCURSO: UMA ABORDAGEM SOCIAL}

Nosso ponto de partida para reflexão sobre a concepção de gêneros do discurso é a proposta por Bakhtin (1997), dado que sua obra é referência para grande parte dos estudiosos sobre esse assunto. $\mathrm{O}$ estudo acerca dos gêneros do discurso requer que o situemos, tal como fez esse filósofo da linguagem, no contexto das atividades humanas, caracterizadas essencialmente pela relação dialógica. Um sujeito, por si só, é incapaz de produzir um diálogo; ele emerge na relação com o outro, e a alteridade de vozes possibilita que a experiência humana seja ressignificada. Enquanto manifestações sóciohistórico-culturais, a linguagem, assim como os gêneros, não pode ser concebida isoladamente das atividades sociais humanas.

Bakhtin (1997, p. 279) conceitua gêneros do discurso como "tipos relativamente estáveis de enunciados" produzidos por cada esfera de utilização da língua. Esses enunciados são determinados pelas especificidades e objetivos de cada domínio discursivo, devendo ser considerado para tal o conteúdo temático; o estilo verbal, ou seja, recursos lexicais, fraseológicos e gramaticais; e a construção composicional. Para esse filósofo da linguagem, a natureza humana é essencialmente social; já a linguagem, por ser ideológica, caracteriza-se pelo constante jogo de oposições que engendra o cenário social no qual o homem se insere.

Importa ressaltar que as manifestações discursivas, verbais e não verbais, são marcadas pela heterogeneidade. Cada esfera de comunicação mantém um repertório de gêneros discursivos que se diferenciam e se ampliam à medida que ela se desenvolve e se complexifica. Para o filósofo, 
Cada esfera conhece seus gêneros, apropriados à sua especificidade, aos quais correspondem determinados estilos. Uma dada função (científica, técnica, ideológica, oficial, cotidiana) e dadas condições, específicas para cada uma das esferas da comunicação verbal, geram um dado gênero, ou seja, um dado tipo de enunciado, relativamente estável do ponto de vista temático, composicional e estilístico. (BAKHTIN, 1997, p. 283-284)

Segundo Rojo (2005), as esferas comunicativas se dividem em dois grandes estratos: as relacionadas ao cotidiano (familiares, comunitárias, etc.) e as dos sistemas ideológicos constituídos (da moral social, da ciência, da arte, da religião, da política, da imprensa etc.). Essa autora destaca o papel dos interagentes de uma esfera de comunicação e os lugares sociais que ocupam:

\begin{abstract}
Em cada uma destas esferas comunicativas, os parceiros da enunciação podem ocupar determinados lugares sociais - e não outros - e estabelecer certas relações hierárquicas e interpessoais - e não outras; selecionar e abordar certos temas - e não outros; adotar certas finalidades ou intenções comunicativas - e não outras, a partir de apreciações valorativas sobre o tema e sobre a parceria. (ROJO, 2005, p. 197)
\end{abstract}

A existência de várias esferas de comunicação requer que os usuários da língua a utilizem de maneiras distintas a fim de atigirem propósitos comunicativos específicos. Isso explica a enorme quantidade de gêneros do discurso que se concretizam nas diferentes situações de uso da linguagem, assim como a complexidade que manifestam.

A vertente social defendida pela teoria bakhtiniana do discurso é um dos pilares do Interacionismo Sociodiscursivo (ISD), corrente fundada por Jean-Paul Bronckart (1999), que se volta para a didática das línguas. Esse autor compreende as ações verbais como mediadoras e constitutivas do meio social. Segundo ele, "as propriedades específicas das condutas humanas são o resultado de um processo histórico de socialização, possibilitado especialmente pela emergência e pelo desenvolvimento dos instrumentos semióticos" (BRONCKART, 1999, p. 21).

A apropriação dos gêneros constitui uma forma de socialização, por meio da qual os sujeitos investem em ações de linguagem. As atividades verbais se realizam por meio de textos empíricos, conforme ele assevera:

\footnotetext{
O texto singular ou empírico, portanto, designa uma unidade concreta de produção de linguagem, que pertence necessariamente a um gênero, composta por vários tipos de discurso, e que também apresenta os traços das decisões tomadas pelo produtor individual em função da sua situação de comunicação particular (BRONCKART, 1999, p. 77).
}

Sob essa ótica, os textos constituem manifestações empíricas das ações de linguagem, que veiculam uma mensagem organizada com vistas a produzir um efeito de coerência sobre o destinatário, em um espaço e tempo determinados. Ao considerar que todo texto é construído com base no modelo de um gênero e que todo texto pertence a um conjunto de textos ou a um gênero, Bronckart (1999, p. 75) preferiu adotar a expressão gênero de texto em vez de gênero do discurso, conforme designação de Bakhtin (1997).

Marcuschi (2008), dialogando com Bakhtin (1997) e Bronckart (1999), também defende o caráter social dos gêneros e observa que os textos "apresentam padrões 
sociocomunicativos característicos definidos por composições funcionais, objetivos enunciativos e estilos concretamente realizados na integração de forças históricas, sociais, institucionais e técnicas" (MARCUSCHI, 2008, p. 155). Por considerar, como Bronckart (1999), que o texto é a materialização do discurso, esse pesquisador também adotou a expressão gêneros textuais.

Vale destacar, dos conceitos explorados por esses autores, alguns fatores determinantes na constituição dos gêneros, quais sejam: suas características sociocomunicativas, seu caráter histórico e social e ainda sua relativa estabilidade, visto que os gêneros podem sofrer alterações de acordo com os interesses comunicativos dos falantes pertencentes a determinada esfera ou domínio discursivo. Em Marcuschi (2008, p. 155), o conceito de domínio discursivo aproxima-se do que Bakhtin (1997) denomina 'esfera da atividade humana' e está relacionado com as instâncias discursivas (discursos acadêmicos, jornalísticos, jurídicos, etc.). Essas instâncias dão origem a um conjunto de práticas discursivas, as quais se consolidam em vários gêneros por vezes legitimados pela comunidade de falantes e instauradores de relações de poder.

Swales $(1990,2004)$ é outro autor que também defende a tese de que a comunicação verbal ocorre por meio de gêneros. Filiado à corrente sociorretórica dos gêneros, seu interesse precípuo consistia em "avaliar os propósitos retóricos, revelar as estruturas da informação e explicar escolhas sintáticas e lexicais.” (SWALES, 1990, p. 3). Esse pesquisador nos oferece uma definição bastante consistente e complexa de gênero:

\footnotetext{
Um gênero compreende uma classe de eventos comunicativos, cujos membros compartilham algum conjunto de propósitos comunicativos. Tais propósitos são reconhecidos pelos experts da comunidade do discurso original e, assim, constituem a lógica para o gênero. Essa lógica molda a estrutura esquemática do discurso e influencia e restringe a escolha de conteúdo e estilo. Propósito comunicativo é tanto um critério privilegiado quanto um que opera para manter o escopo de um gênero como aqui concebido estritamente focado em ação retórica comparável. Além do propósito, exemplares de um gênero exibem vários padrões de similaridade em termos de estrutura, estilo, conteúdo e público-alvo. Se todas as altas expectativas de probabilidade forem realizadas, o exemplar será visto como prototípico pela comunidade do discurso original. Os nomes do gênero herdados e produzidos por comunidades de discursos e importados por outros constituem comunicação etnográfica valiosa, mas normalmente requerem mais validação. (SWALES, 1990, p. 58, tradução nossa)
}

Essa definição nos leva a compreender que, como classe de eventos comunicativos, os gêneros são categorizados a partir de padrões formais e/ou contextuais recorrentes nas ações de linguagem. A linguagem se constitui pelo discurso, seus agentes, sua função bem como pelo contexto de produção e recepção. Os propósitos comunicativos ganham destaque na concepção do autor, que considera os gêneros, salvo algumas exceções, como "veículos comunicativos para a concretização de objetivos" (SWALES, 1990, p. 46). É importante ressaltar que um gênero pode compartilhar mais de um propósito comunicativo, que nem sempre se manifestam explicitamente ou podem ser claramente identificados. Quanto à comunidade de discurso, esta se constitui de um conjunto de pessoas que compartilham entre si um grupo de repertórios de gêneros com traços retóricos bem definidos e que têm como função social a validação das atividades interacionais, assim como a capacidade de produzir novos gêneros. (BIASIRODRIGUES; ARAÚJO; SOUZA, 2009, p. 31-32). 
Como pedagogo, as reflexões de Swales (1990; 2004) incidem sobre o trabalho com gêneros acadêmicos. $\mathrm{O}$ autor defende sistematicamente a necessidade de capacitar os aprendizes no mundo da pesquisa de forma que eles se tornem proficientes linguística e socialmente nas diferentes atividades acadêmicas. Para ele, as práticas de comunicação e identidades sociais são adquiridas somente por meio da imitação das atividades comunicativas ocorridas na comunidade acadêmica. Suas considerações são de suma importância nesta pesquisa, principalmente quando nos propomos tratar de letramentos acadêmicos, como será visto a seguir.

\section{GÊNEROS ACADÊMICO-CIENTÍFICOS E PRÁTICAS DE LETRAMENTO}

Swales (2004) considera os gêneros acadêmico-científicos como produtos e processos comunicativos decorrentes da interação em ambientes educacionais. Do artigo de pesquisa escolar à palestra universitária informal, o autor analisa modelos estruturais de gênero, suas relações intertextuais e sua comunidade acadêmica. $\mathrm{O}$ autor traz as contribuições de Fichelov's (1993) acerca das metáforas de gênero e discorre sobre a distribuição e inter-relação de gêneros, bem como seus cenários locais e conexões institucionais. Entre tais metáforas, destaca-se a concepção de gêneros como frames, emprestada de Bazerman (1997, p 19), para quem os gêneros são ambientes de aprendizagem nos quais o significado é construído e os pensamentos que formamos assim como as comunicações por meio das quais interagimos são configuradas. Sob essa perspectiva, os gêneros podem ser compreendidos como um procedimento sociocognitivo, visto que favorecem construções retóricas diferentes, práticas de pesquisa e ações sociais por parte da comunidade.

Nessa mesma linha de raciocínio, Kay e Dudley-Evans (1998, p. 310) chamam a atenção para o fato de que os gêneros constituem uma ferramenta pedagógica muito poderosa, já que eles proporcionam uma visão dos tipos de discurso que eles precisam compreender e produzir na fala e na escrita. Além disso, possibilitam uma compreensão de por que um discurso é do jeito que é, por meio de uma consideração de seu contexto social e de seu propósito. Ressaltamos que é possível que diferentes discursos se manifestem em exemplares distintos de um mesmo gênero. Contudo, os gêneros acadêmico-científicos definem bem seu tipo de discurso na esfera científica e o monitoramento docente, em ambiente escolar ou acadêmico, também contribui para isso.

Swales (1990, 2004) observa que o êxito dos alunos graduandos e pós-graduandos está intrinsecamente relacionado com o desenvolvimento de habilidades de leitura e produção dos gêneros que emergem e constituem a cultura acadêmica, expressa pela legitimação de vozes sociais, da cultura e das relações de poder características dessa comunidade. Daí a importância de que sejam engajados em atividades de pesquisa que integrem os sujeitos, os objetos de conhecimento e os instrumentos necessários a esse empreendimento.

A partir de contribuições de diferentes construtos teóricos, sobretudo os que defendem a natureza social dos gêneros, Bezerra (2012, 2015) e Araújo e Bezerra (2013) refletem sobre a estreita relação entre o conceito de gênero e as práticas e eventos de 
letramento. Para os autores, as relações humanas estabelecidas a partir da escrita ocorrem por meio de gêneros textuais que circulam em uma comunidade linguística, cujos participantes necessitam desenvolver habilidades específicas de letramento para atuarem nela com proficiência. Assim sendo, para que os estudantes se engajem em eventos de letramento acadêmico, é fundamental que eles se apropriem das práticas discursivas características de sua comunidade, que envolvem linguagem e conhecimentos científicos específicos, bem como capacidade de pesquisa e de argumentação, entre outros requisitos.

Lea e Street (apud BEZERRA, 2012, p. 248) observam que "a aprendizagem no ensino superior implica a adaptação a novas formas de saber: novas maneiras de compreender, interpretar e organizar o conhecimento". Entretanto, para que ocorra a produção de conhecimento na esfera científico-acadêmica, é fundamental que os docentes universitários motivem os graduandos a desenvolver atividades de pesquisa, cujos resultados sejam apresentados em forma de textos acadêmicos, entre os quais podemos citar o resumo, a resenha, o ensaio, o Trabalho de Conclusão de Curso - TCC e o artigo científico. Figueiredo e Bonini (2006, p. 417) refletem sobre a dificuldade de muitos alunos graduandos e pós-graduandos em sistematizar o conteúdo pesquisado em gêneros acadêmicos. Além de apresentarem dificuldades relacionadas às habilidades linguísticas, eles também não têm domínio da estrutura composicional dos gêneros e de seu conteúdo temático, em que se requer o desenvolvimento de um raciocínio argumentativo e/ou expositivo fundamentado na apreciação de teorias, análise de fatos, exposição de ideias e elaboração de conclusões. Considerando que essas habilidades são essenciais para a formação de um sentimento de pertencimento à comunidade discursiva acadêmica, essa falta de autonomia acarreta a ausência de uma identidade com esse meio e um distanciamento do aluno das atividades de pesquisa, tão essenciais para que ele desenvolva sua capacidade investigativa e de aprender a aprender.

Esse alheamento em relação às atividades de pesquisa na universidade, bem como ao domínio de gêneros que circulam na esfera acadêmica, torna-se ainda mais evidente se considerarmos que, na educação básica, as atividades de pesquisa também não são estimuladas e tampouco consideradas como uma proposta educativa, embora os documentos oficiais brasileiros orientem nesse sentido. A consequência é que os alunos chegam ao ensino superior com pouca bagagem intelectual, necessária para sua inserção no universo da pesquisa. A universidade torna-se um espaço de múltiplas possibilidades a ser descoberto e o tempo da integralização de uma grade curricular no ensino superior acaba sendo pouco para que os alunos construam uma identidade cultural e um sentimento de pertencimento à comunidade acadêmica.

Chamamos a atenção para o artigo 22 da LDB n ${ }^{\circ}$ 9394/96, segundo o qual a educação básica deve oferecer aos educandos os meios necessários para progressão no trabalho e em estudos posteriores. As teorias construtivistas (PIAGET, 1976) e socioconstrutivistas (VYGOTSKY, 1984) reforçam a importância e a necessidade de se investir em projetos de educação em que o aluno seja o agente da própria aprendizagem em superação a um modelo tradicional segundo o qual o professor atua como centralizador e transmissor do conhecimento. A inserção de atividades de pesquisa nos currículos escolares da educação básica oportuniza que os alunos abandonem a passividade de uma educação bancária (FREIRE, 2005), conquistando sua própria autonomia enquanto leitores e produtores de textos científicos. 
A Base Nacional Comum Curricular - BNCC (BRASIL, 2018), documento que define o conjunto das aprendizagens essenciais ao longo das etapas e modalidades da educação básica, inclui as atividades de pesquisa como uma das oito competências gerais a serem desenvolvidas pelos alunos:

2. Exercitar a curiosidade intelectual e recorrer à abordagem própria das ciências, incluindo a investigação, a reflexão, a análise crítica, a imaginação e a criatividade, para investigar causas, elaborar e testar hipóteses, formular e resolver problemas e criar soluções (inclusive tecnológicas) com base nos conhecimentos das diferentes áreas. (BRASIL, 2018, p. 9).

Ganha destaque o caráter científico, o rigor metodológico e a abordagem inter e transdisciplinar da pesquisa, que, além de ser um compromisso de cada área, deve perpassar conhecimentos de todas as demais, por meio de ações que envolvem a leitura, a seleção e validação de dados por meio de um método específico, bem como o tratamento e organização das informações. Para a BNCC, a pesquisa

\begin{abstract}
[...] inclui tanto procedimentos relacionados à busca simples (mas confiável) de informações, envolvendo comparações e seleções, para responder diretamente a uma questão - um dos sentidos do termo "pesquisa" -, quanto procedimentos que envolvem algum método para a busca mais minuciosa e acurada de respostas a questões mais complexas, não respondíveis diretamente. (BRASIL, 2018, p. 515).
\end{abstract}

Trazemos para esse diálogo a afirmação de Paulo Freire, segundo o qual "não há ensino sem pesquisa e pesquisa sem ensino" (FREIRE, 2001, p. 32). Cabe ao educador estimular os saberes dos educandos por meio do exercício da curiosidade, que os instiga à imaginação, observação, questionamento, elaboração de hipóteses e a uma explicação epistemológica. É por meio da construção do conhecimento que o homem irá compreender sua relação com a natureza e com os outros homens, podendo, desse modo, agir e transformar a realidade.

A BNCC, no âmbito da língua portuguesa, determina que o campo das práticas de estudo e pesquisa seja constitutivo dos anos iniciais e finais do ensino fundamental e de todo o ensino médio. No ensino médio, esse campo "abrange a pesquisa, recepção, apreciação, análise, aplicação e produção de discursos/textos expositivos, analíticos e argumentativos, que circulam tanto na esfera escolar como na acadêmica e de pesquisa, assim como no jornalismo de divulgação científica." (BRASIL, 2018, p. 488-489).

A BNCC destaca diferentes gêneros, suportes e mídia impressa ou digital que constituem objeto de conhecimento contextualizado para a socialização dos estudos e pesquisas ao longo de todas as etapas da educação básica. Entre eles, podemos citar os eminentemente orais (seminário, apresentação, debate, mesa-redonda, etc.), os escritos (relatos de experimentos, quadros sinópticos, gráficos, tabelas, infográficos, diagramas, entrevistas, notas de divulgação científica, verbetes de enciclopédia, relatórios, esquemas, resumos, artigo de divulgação científica, artigo científico, ensaio, monografia, etc.) e os multissemióticos (cartografia animada, videominuto, documentário, vlog científico, podcast, relato multimidiático de campo, verbete de enciclopédia digital colaborativa, revista digital, fotorreportagem, foto-denúncia etc.). 
A implementação de práticas de letramento que envolvem o estudo e a pesquisa facilita o desenvolvimento de competências e habilidades de leitura e escrita, a capacidade de questionar, maior compreensão do funcionamento sociocomunicativo dos gêneros discursivos característicos dessa esfera comunicativa, a expressão de autoria, bem como maior identificação com o universo da pesquisa. Nesse sentido, é fundamental que os alunos da educação básica sejam orientados para a leitura e escrita desses tipos de textos, respeitados os níveis de maturação e de aprendizagem em que se encontram.

Um trabalho com pesquisas e práticas na educação básica que favoreça situações vivenciais voltadas para a formação dos educandos certamente proporcionará, entre outras vantagens, menor distanciamento e maior integração entre os diferentes níveis de ensino; o investimento em processos formativos e de atenção aos contextos das práticas escolares; e melhor preparo do aluno para ingresso na educação superior. A realização competente de eventos de letramento nessa modalidade de ensino facilitará sobremaneira, na graduação, a participação dos graduandos nas atividades e procedimentos atinentes às esferas científicas, a autonomia no exercício dessas práticas, a construção de uma identidade com sua comunidade de discurso, bem como a compreensão da importância desse aprendizado para o prosseguimento dos estudos e formação para o trabalho.

\section{PERCURSO METODOLÓGICO}

O objetivo da pesquisa realizada foi refletir sobre o conhecimento dos alunos iniciantes em um curso de graduação sobre os gêneros acadêmicos e a percepção destes quanto às práticas de letramento acadêmico. Consideramos, para isso, a pergunta-chave: Quais são as concepções e as expectativas sobre práticas de letramento acadêmico internalizadas pelos alunos ingressantes em um curso de graduação em Letras? Nossa hipótese foi que a ausência de desenvolvimento de atividades de pesquisa na educação básica e também a pouca familiaridade com gêneros acadêmicos constituem obstáculos para o desenvolvimento de práticas de letramento na graduação.

A metodologia adotada, quanto ao objetivo específico, foi a pesquisa explicativa, com vistas a identificar, registrar e analisar as causas do fenômeno estudado (GIL, 2019). Para alcance dos resultados, recorremos tanto a procedimentos de análise experimental/quantitativa quanto de análise qualitativa. $\mathrm{O}$ corpus analisado consistiu de um questionário constituído de 8 (oito) perguntas, aplicado a 28 (vinte oito) alunos recémingressos em um curso de Letras com especialidade em tecnologias de edição, ofertado por uma escola da rede federal de ensino em Minas Gerais, em sua primeira aula da disciplina Oficina de Texto Acadêmico e Comunicação Científica, ministrada no primeiro semestre de 2020.

Os resultados sinalizam baixo grau de conhecimento, por parte dos alunos, acerca do funcionamento sociocomunicativo dos gêneros acadêmicos, embora eles validem a importância de tais conhecimentos em sua carreira profissional. Este trabalho se justifica, pois oportuniza maior reflexão e compreensão de como a prática da pesquisa e o agir discursivo por meio dos gêneros acadêmicos, ainda na educação básica, respeitados os níveis de aprendizagem, podem favorecer aos alunos graduandos a construção de conhecimentos, a formação de uma consciência em relação à atuação social da academia, bem como uma sensação de pertencimento ao ambiente acadêmico. 
O questionário aplicado aos recém-ingressos na faculdade de Letras consistiu das seguintes perguntas:

1. Um dos objetivos da universidade é a construção do conhecimento. O que você compreende como produzir conhecimento na universidade?

2. O nome desta disciplina é "Oficina de Texto Acadêmico e Comunicação Científica". O que você compreende como gêneros textuais acadêmicos?

3. Ao longo de sua formação estudantil, relacione alguns gêneros acadêmicos que você costumava ler e produzir.

4. Que desafios (ou dificuldades) você encontrava para ler e produzir os gêneros relacionados na questão anterior?

5. Que características ou qualidades um bom texto acadêmico deve possuir?

6. Quais habilidades ou conhecimentos você julga imprescindíveis para a leitura e a produção de gêneros textuais acadêmicos?

7. Que importância você atribui ao domínio desses gêneros para sua vida acadêmica?

8. Que importância você atribui ao domínio desses gêneros para a carreira profissional que você escolheu?

\section{Quadro 1 - Atividade diagnóstica}

Fonte: Dados dos autores

Optamos por fazer um questionário com respostas abertas, de modo a permitir que o respondente expressasse espontaneamente seus conhecimentos ou opiniões sem que suas respostas fossem induzidas a partir de opções preestabelecidas. Isso tornaria mais verossímil a pesquisa a que nos propusemos. Os insumos foram tabulados e processados em planilhas eletrônicas elaboradas no Excel, um editor da Microsoft. Os resultados obtidos foram interpretados mediante análise dos dados, considerando-se, para tal, a frequência das respostas apresentadas pelos respondentes.

Optamos por fazer um recorte das perguntas e dos dados categorizados; assim, foram descritas e analisadas somente as questões de $n^{\circ}$ 2, 4, 5 e 8. Essa escolha decorreu da complexidade dos resultados obtidos, do espaço do artigo, ainda pelo fato de que essas questões, por focalizarem conteúdos relativos aos gêneros acadêmicos e suas expectativas em relação a letramento acadêmico, ajudam-nos a compreender melhor o nível de conhecimento dos graduandos sobre essa abordagem.

Passaremos à exposição e discussão dos dados destacados para, em seguida, tecermos nossas considerações sobre eles.

\subsection{A PERSPECTIVA DOS ALUNOS RECÉM-GRADUANDOS}

A questão 2 do questionário solicitava que os recém-graduandos respondessem o que eles compreendiam como gêneros textuais acadêmicos. A categorização dos dados foi feita considerando-se, principalmente, a noção de gêneros proposta por Bakhtin (1997) e Swales (1990; 2004), com destaque para o conteúdo temático/propósito comunicativo, a construção composicional, estilo, exemplos de gêneros, agentes e esfera de circulação. O Quadro 2 mostra os resultados obtidos: 


\begin{tabular}{|c|c|c|c|}
\hline Conteúdo temático/Propósito & Índices & Construção composicional & Índices \\
\hline $\begin{array}{l}\text { Comunicação / propagação do } \\
\text { conhecimento }\end{array}$ & 9 & Formas de texto & 3 \\
\hline Estudo e Pesquisa acadêmica & 7 & Tipos textuais & 1 \\
\hline Compreensão e interpretação de textos & 2 & Atributos factíveis & 1 \\
\hline Objetivo único & 1 & Produções literárias & 1 \\
\hline Estilo & Índices & Exemplos de gêneros & Índices \\
\hline Norma culta & 1 & Resenhas & 6 \\
\hline Formalidade & 2 & Resumos & 3 \\
\hline \multirow[t]{12}{*}{ Expressões técnicas } & 1 & Artigo acadêmico & 7 \\
\hline & & Monografias & 3 \\
\hline & & Dissertações & 3 \\
\hline & & Teses & 3 \\
\hline & & TCC & 4 \\
\hline & & Ensaios & 1 \\
\hline & & Conto & 1 \\
\hline & & Crônica & 2 \\
\hline & & Poesia & 1 \\
\hline & & Projetos & 1 \\
\hline & & Roteiro & 1 \\
\hline & & Relatórios técnicos & 1 \\
\hline Esfera de circulação & Índices & Agentes & Índices \\
\hline Universidade & 8 & Alunos & 3 \\
\hline Faculdade & 1 & Professores & 1 \\
\hline Graduação & 1 & Autor & 1 \\
\hline Academia & 1 & & \\
\hline Meio educacional & 1 & & \\
\hline Outros ambientes & 4 & & \\
\hline $\begin{array}{l}\text { Campo de conhecimento que chamamos de } \\
\text { ciência }\end{array}$ & 1 & & \\
\hline
\end{tabular}

\section{Quadro 2 - Definição de gêneros textuais acadêmicos}

Fonte: Dados dos autores.

Em relação ao conteúdo temático/propósito comunicativo, chamou-nos a atenção o número de respostas relacionadas à comunicação, conhecimento e pesquisa acadêmica. Entretanto, tal ocorrência se dá precipuamente por paráfrases da própria questão, não significando necessariamente um conhecimento sistematizado sobre o assunto, conforme elucidam os seguintes trechos de enunciados:

- “[...] tem como objetivo aproximar e tornar mais fácil a comunicação entre alunos e professores [...]";

- “[...] gêneros em que se propõem respostas e resultados de informações dadas mediante pesquisas $[\ldots]$ "..;

- “[...] gêneros voltados ao desenvolvimento e propagação de conhecimento [...]”.

As definições sobre gênero foram escassas, conforme pudemos observar em relação à construção composicional, referenciada com apenas seis índices, sendo que, entre eles, pôde-se verificar certa confusão de terminologia com a menção a tipos textuais e a produções literárias. As informações relativas ao estilo especificam a preferência pelo uso 
da modalidade culta da língua, comumente exigida nas atividades escolares, principalmente em textos formais. Quanto aos exemplos de gêneros citados, sobressaem os estritamente acadêmicos, entre os quais se destacam a resenha e o artigo acadêmico (expressão citada nas respostas). Entretanto, chamou-nos à atenção a recorrência de gêneros literários, que, embora sejam objeto de conhecimento na graduação em Letras, apresentam, entre outros fatores, propósito comunicativo diferente daquele dos gêneros acadêmicos.

Quanto à esfera de circulação, ganha notoriedade o ambiente acadêmico, certamente pelo adjetivo especificador dos gêneros em estudo. Atentamos para a referência a outros ambientes, embora estes sejam especificados vagamente, como "ambientes parecidos" e "outros setores da sociedade". O uso de tais expressões pode sugerir o intercâmbio de conhecimentos e experiências entre o universo acadêmico e outras instâncias sociais.

Já a referência aos agentes circunscreveu-se basicamente aos sujeitos comumente presentes na sala de aula, física ou virtualmente. Não houve nenhum destaque, por exemplo, aos agentes responsáveis pelo funcionamento da biblioteca escolar e pelos departamentos de pesquisa e extensão, que cuidam da preparação e divulgação de editais de projetos, bem como pela divulgação científica e tecnológica, entre outras ações. Também não há nenhuma referência a grupos de pesquisa, comitês de ética, tampouco a instituições de fomento. Ressalta-se, com isso, o desconhecimento de que os objetivos de uma comunidade acadêmica não se restringem a práticas de ensino e aprendizagem em sala de aula, envolvendo também atividades de pesquisa e extensão que se expandem para outros departamentos da instituição e para além de suas dependências.

A questão 4 visava a mapear os desafios ou dificuldades encontradas pelos graduandos no ato de leitura e produção de gêneros acadêmicos. Foram elencados os seguintes descritores (Quadro 3):

\begin{tabular}{|l|r|l|r|}
\hline Leitura & Índices & Produção & Índices \\
\hline Termos técnicos/linguagem formal & 8 & $\begin{array}{l}\text { Desconhecimento dos aspectos temático- } \\
\text { composicionais dos gêneros }\end{array}$ & 10 \\
\hline Dificuldade de compreensão & 6 & Problemas de coerência e coesão textual & 12 \\
\hline $\begin{array}{l}\text { Déficit de aprendizagem na educação } \\
\text { básica }\end{array}$ & 5 & $\begin{array}{l}\text { Domínio de vocabulário / linguagem } \\
\text { formal }\end{array}$ & 2 \\
\hline Dificuldade de concentração & 1 & Desconhecimento das regras da ABNT & 2 \\
\hline Falta de acesso a livros e à internet & 1 & Falta de ensino/incentivo & 6 \\
\hline Textos escritos em idiomas & 1 & Ensino médio defasado & 1 \\
\hline & & Temas desinteressantes & 1 \\
\hline & & Falta de tempo & 1 \\
\hline & & Receio quanto a plágio & 1 \\
\hline
\end{tabular}

\section{Quadro 3 - Desafios encontrados para a leitura e produção de gêneros textuais acadêmicos}

Fonte: Dados dos autores. 
Os dois primeiros itens do quadro relacionados à leitura evidenciam a pouca familiaridade dos graduandos com os gêneros acadêmicos e as convenções comunicativas que circulam na comunidade acadêmica, o que acarreta dificuldade de compreensão textual. Essa dificuldade, entretanto, não reside apenas no fato de os graduandos se encontrarem em um ambiente ainda novo e desconhecido para eles. Sob esse ponto de vista, essa desestabilização seria normal, visto que eles estão no início de uma nova etapa, em que se faz necessária a assimilação crítica de novos conceitos e construção de conhecimentos essenciais a seu processo de formação. $O$ déficit de aprendizagem na educação básica também é um indicador expressivo na pesquisa e sinaliza a falta de domínio de conceitos científicos basilares para sua aprendizagem, a ausência de habilidades e estratégias essenciais para a construção do saber e resolução de problemas, bem como a capacidade de se posicionar criticamente diante dos fatos e das leituras realizadas.

Situação semelhante pudemos encontrar nos insumos relativos à produção de gêneros acadêmicos, que também sinalizam o baixo índice de conhecimento deles e de seu funcionamento sociocomunicativo. É o que se pode depreender dos seguintes trechos de enunciados:

- " “...] compreender as diferenças entre gêneros como fichamentos, resumos e resenhas."

- " "[...] entender as diferenças entre gêneros (resenha $\mathrm{x}$ crítica) [...]"

- "[...] apresentar ideias claras, objetivas e coerentes [...]"

- " "[...] apresentar as informações de forma correta e com coesão."

A ausência de uma aprendizagem significativa, que possibilite maior domínio da produção textual dos gêneros e uma ancoragem para novos conhecimentos, também fica evidente nos seguintes trechos de enunciados:

- "[...] falta de incentivo a reconhecer, estudar e produzir textos acadêmicos [...]"

- "[...] falta de ensino de realmente como produzir textos [...]"

- " "...] ensino médio extremamente defasado, raso."

Observe-se, por esses dois conjuntos de informações retirados da pesquisa, que as dificuldades se concentram não só nos aspectos temáticos, discursivos, estilísticos e composicionais dos gêneros, como também em outros relativos à clareza, objetividade, concisão, coerência e coesão que envolvem a produção textual. Em outras palavras, a defasagem na redação de textos transcende o conhecimento dos gêneros acadêmicos e envolve a falta de conhecimento dos fatores de textualidade e o domínio das habilidades de escrita. Embora sejam conteúdos previstos nos documentos legais de ensino de língua portuguesa e apresentados nos manuais didáticos, os alunos sentem que não construíram uma aprendizagem efetiva destes. Os dados apresentados denunciam a deficiência de aprendizagem e a ausência de motivação na educação básica como fatores responsáveis pela falta de habilidades para dominar um procedimento de escrita consistente, consciente e autônomo.

Investigamos, na questão 5, qual o grau de consciência dos recém-graduandos quanto às características ou qualidade de um bom texto acadêmico. Para a sistematização das informações, recorremos à teoria dos gêneros discursivos (BAKHTIN, 1997; SWALES, 1990, 2004) e da Linguística Textual (KOCH, 2000, 2008). As principais respostas para essa pergunta foram assim catalogadas (Quadro 4): 


\begin{tabular}{|l|r|}
\hline Características de um bom texto acadêmico & Índices \\
\hline Gêneros - Aspectos temáticos & 26 \\
\hline Gêneros - Aspectos Composicionais & 6 \\
\hline Gêneros - contexto sociocomunicativo & 2 \\
\hline Coerência & 9 \\
\hline Coesão / Domínio da escrita & 8 \\
\hline Clareza & 17 \\
\hline Concisão / objetividade & 9 \\
\hline Correção / linguagem formal & 3 \\
\hline Referências bibliográficas & 4 \\
\hline Observância às normas da ABNT & 2 \\
\hline
\end{tabular}

\section{Quadro 4 - Características de um bom texto acadêmico}

Fonte: Dados dos autores.

As respostas oferecidas não refletem nenhum conhecimento aprofundado dos conteúdos e teorias abordadas, tampouco boa articulação de ideias e argumentos expressos, mas são importantes para indiciar conhecimentos prévios e aspectos de cognição situada. Quanto aos aspectos temáticos dos gêneros, sobressaem insumos do tipo "objetivos tangíveis de serem pesquisados", "bom referencial teórico", "apresentar fatos, hipóteses bem elaboradas, propostas de reflexão" e "apresentar conclusões, propor soluções, investigações e continuidade da pesquisa desenvolvida". Em relação aos aspectos composicionais, registram-se dados como "fidelidade ao gênero de texto" e "estrutura adequada de acordo com o gênero", no entanto não há referência a nenhum gênero específico, muito menos a elementos que definem seu acabamento geral. Quanto ao contexto sociocomunicativo, encontramos duas vagas referências: "contexto importante e necessário de acordo com o tema" e "proximidade com o receptor do texto", o que também não contribui muito para se afirmar que há um conhecimento elaborado sobre a questão.

Coerência e coesão textual (KOCH, 2000, 2008) são dois fatores de textualidade muito trabalhados na educação básica, principalmente nos anos finais do ensino médio, quando os alunos se preparam para os exames de seleção para o ensino superior. O mesmo pode-se dizer a respeito de clareza, concisão, objetividade e correção, elementos essenciais que nortearão o estilo de linguagem exigido nas escolas para a redação técnicocientífica. O objetivo almejado é a produção de textos bem estruturados, com parágrafos devidamente organizados, por meio de elementos coesivos apropriados e ideias expressas em sequências claras, lógicas e objetivas, de modo a configurar um todo coerente e coeso. As respostas dadas evidenciam que os alunos desenvolveram a consciência do que é um bom texto, embora isso, por si só, não seja garantia de uma boa escrita, conforme já destacado nas respostas das questões anteriores.

Outro aspecto recorrente nas respostas dadas foram as referências bibliográficas e as normas da ABNT. Os alunos devem ser estimulados a produzir textos não de forma artificial, mas a partir de um processo de ensino-aprendizagem contextualizado e de pesquisa em diferentes fontes bibliográficas, para que possam expandir o conhecimento, confrontar ideias, construir seus próprios pontos de vista e organizá-los em textos de 
acordo com as normas de padronização técnica. Atividades que exijam esse grau de complexidade lhes permitirão ampliar sua capacidade de análise e reflexão, o desenvolvimento do pensamento abstrato, do raciocínio crítico, as habilidades de pesquisa e sistematização do conhecimento por meio de linguagens, símbolos e códigos apropriados.

A questão 8 buscou observar as expectativas dos graduandos quanto à aprendizagem e ao domínio dos gêneros acadêmicos para a carreira profissional. Em síntese, as respostas dadas foram as seguintes (Quadro 5):

\begin{tabular}{|l|r|}
\hline Importância quanto ao domínio gêneros para a carreira profissional & Índices \\
\hline Favorecem a atuação profissional & 13 \\
\hline Favorecem a construção da carreira profissional & 7 \\
\hline Contribuem para a elaboração e a troca de novos conhecimentos e informações & 11 \\
\hline Contribuem para a atuação na área da pesquisa & 5 \\
\hline
\end{tabular}

\section{Quadro 5 - Importância do domínio dos gêneros para a carreira profissional}

Fonte: Dados dos autores.

Os trechos de enunciados das respostas exemplificam as ideias resumidas acima:

a) Atuação profissional:

- "[...] favorece a execução de trabalhos nas funções de editor, tradutor e redator."

- " "...] favorece a execução de trabalhos como revisor de textos."

- "[...] ajuda a crescer como profissional na carreira acadêmica."

- "[...] sustentam a profisssão de jornalismo e comunicação."

b) Construção da carreira profissional:

- "[...] favorece a inserção e atuação no mercado de trabalho [...]"

- "[...] pré-requisito para um bom profissional na área [...]"

c) Elaboração e troca de novos conhecimentos e informações:

- "[...] aprofundamento técnico e científico [...]"

- "[...] ajuda a desenvolver o senso crítico, o foco e a coerência [...]"

- "[...] estimula o ciclo do conhecimento [...]"

- "[...] favorece a troca de conhecimentos [...]"

d) Atuação na área da pesquisa:

- “[...] favorece a pesquisa e a discussão sobre vários assuntos."

- "[...] auxilia nas atividades de pesquisa [...]"

Essas respostas especificam o campo de atuação dos graduados no curso de Letras com ênfase em tecnologias de edição. A profissão lhes permite atuar como editores e revisores de textos em diversos suportes e diferentes mídias. Também poderão ocupar cargos de gestores e assistentes editoriais, assessores culturais, entre outros. Caso optem pelo campo de licenciatura, poderão fazer complementação do curso na própria universidade e, se quiserem investir em pesquisa, a instituição oferece mestrado e doutorado na área. 
Ressaltamos que as respostas apresentadas foram bastante genéricas e sem muita consistência. Os respondentes não se preocuparam em refletir, por exemplo, sobre como, em que medida e em quais aspectos o conhecimento dos gêneros acadêmicos poderá ajudá-los no exercício da profissão. Também não manifestaram nenhum comentário sobre a socialização dos conhecimentos em eventos ou publicações de natureza científica, prática fundamental para a divulgação de pesquisas realizadas. A ausência de informações desse tipo especifica o baixo grau de consciência dos alunos relativo tanto à importância da aprendizagem dos gêneros acadêmicos para a consolidação de sua carreira profissional, quanto aos propósitos comunicativos desses gêneros. Sinaliza também a necessidade de as instituições investirem em práticas de pesquisa e em atividades de letramento que possam contribuir para a construção de uma expressão de identidade dos graduandos com a comunidade acadêmica e suas manifestações discursivas.

\subsection{UM OLHAR PARA ALÉM DOS DADOS}

Os dados e as considerações feitas com base na investigação realizada estimulamnos a propor algumas reflexões sobre práticas de letramento necessárias para a formação de sujeito pesquisador, crítico e autônomo em suas leituras e produções. Enfatizamos, nesse sentido, as contribuições de Bakhtin (1997), Bronckart (1999) e Marcuschi (2008) sobre os gêneros discursivos, e as de Swales (1990; 2004) quanto à aprendizagem dos gêneros acadêmicos. Dois aspectos básicos mereceram nossa atenção especial, pelas implicações com os resultados focalizados: a necessidade de uma formação consolidada sobre gêneros que integram a pesquisa na educação básica e a expectativa dos recémgraduandos em relação ao letramento acadêmico na graduação.

A demanda por práticas pedagógicas que estimulem a aprendizagem por meio de pesquisas na educação básica tem se constituído como objeto de reflexão de vários pesquisadores, principalmente aqueles alinhados à proposta socioconstrutivista de Vygotsky (1984). Tais estudiosos acreditam estar superado um modelo de ensinoaprendizagem focado na ação do professor transmissor do conhecimento. Esse modelo consiste na apresentação de um conjunto de regras constituintes de um conjunto de referências essenciais para que os alunos possam se empenhar na resolução de tarefas escolares. Esse método de ensino mecanicista sofre severas críticas por desconsiderar os conhecimentos prévios, a criatividade, a capacidade de pesquisa e de reflexão dos alunos, bem como suas oportunidades de participar e de interagir ativamente na construção de conhecimentos que os conduzirão à elaboração de novas aprendizagens. Na educação básica, a pesquisa deve envolver tanto os conhecimentos científicos já consolidados nas práticas de referência, como a produção de novos conhecimentos atinentes a seu contexto histórico-social.

A implementação de práticas de pesquisa na educação básica implica necessariamente o ensino e a aprendizagem de gêneros acadêmico-científicos essenciais para a formalização dos conhecimentos construídos. As práticas de letramento devem considerar tanto os gêneros convencionalmente instituídos (resumo, resenha, relatório científico, etc.) como outros que facilitam a síntese, a contextualização, a interpretação e a generalização de dados, como a tabela, o gráfico, o infográfico, etc. Igualmente importantes, mas que nem sempre gozam do mesmo prestígio, embora também devam ser ensinados, são os gêneros utilizados em eventos acadêmico-científicos para 
apresentações verbo-visuais, como a exposição acadêmica, a conferência, o debate, entre outros. Uma abordagem de letramento em gêneros articulada com as práticas de pesquisa é importante, sobretudo porque possibilita a contextualização do ensino e a formação do raciocínio crítico e investigativo, que favorecerão o desenvolvimento de habilidades.

Ao organizar o currículo por campos de atuação, a BNCC (BRASIL, 2018) criou o campo das práticas de estudo e pesquisa, que, nos estudos de Língua Portuguesa, pode favorecer a organização dos saberes, bem como a articulação destes com outras áreas de conhecimento e com outros projetos e escolhas pessoais. Também poderá contribuir para a participação dos estudantes em projetos de iniciação científica bem como a demonstração de trabalhos em feiras de ciências e outros eventos dessa natureza, possibilitando o contato com ricas e diversificadas experiências dentro e fora do ambiente escolar. Entre outras, a expectativa é a implementação e o aperfeiçoamento de práticas pedagógicas que encaminhem propostas de investigação com vistas à solução de problemas e à aprendizagem autônoma.

O desenvolvimento de atividades de pesquisa integradas aos estudos dos gêneros discursivos inerentes a ela, bem como a participação em eventos de natureza científica, podem constituir um diferencial para os estudantes recém-ingressos nas instituições de ensino superior. Isso porque as habilidades trabalhadas na educação básica lhes favorecerão o exercício do pensamento científico, crítico e criativo, fundamental para investigação de fatos, elaboração e testagem de hipóteses, formulação, resolução e proposição de soluções para as questões e problemas com os quais se defrontarão em sua rotina acadêmica.

Entretanto, como outras pesquisas apontam, a falta de autonomia dos graduandos em relação à investigação científica e ao domínio adequado dos gêneros acadêmicos é um fato indiciador de que a prática da pesquisa também não está consolidada nos cursos de graduação. Lüdke e Cruz (2005) observam que a formação para a pesquisa na graduação fica sob o encargo de alguns docentes pesquisadores, que selecionam alunos com vistas à participação em grupos de pesquisa, atividades de monitoria, pesquisa de campo, participação em eventos científicos, etc. Aranha (2009) denuncia a ausência de disciplinas nas grades curriculares dos cursos voltadas para o desenvolvimento das habilidades de escrita dos alunos, ainda que a publicação dos resultados de suas pesquisas seja desejável.

Bezerra (2015) destaca a importância de um envolvimento ascendente dos graduandos com a leitura e a produção dos gêneros relacionados à pesquisa para a construção da sua identidade como participante legítimo e legitimado da comunidade acadêmica. Motta-Roth (1999) argumenta que o uso dos gêneros na academia mantém e medeia o saber instituído, sendo necessário o desenvolvimento de uma consciência sociorretórica por parte dos alunos e dos professores sobre as diferentes possibilidades do discurso. A participação ativa e a permanência dos graduandos na academia só se efetivarão se eles se apropriarem das convenções sociocomunicativas e pragmáticas dessa comunidade, o que implica o desenvolvimento das habilidades de letramento indispensáveis para a construção de uma identidade com a academia.

Em síntese, se almejamos que nossas escolas formem sujeitos pesquisadores e uma cultura da pesquisa, precisamos pensar em um continuum de ações que envolvam tanto a educação básica quanto a superior, ou ambas em conjunto na busca de soluções que possam maximizar as atividades com foco nesse segmento. Uma série de medidas pode ser tomada nesse sentido, a saber: 
a) organização das grades curriculares dos cursos superiores, entre eles os de licenciatura, que irão formar novos professores para atuar na educação básica. É fundamental que, nas matrizes dos cursos, sejam inseridas disciplinas voltadas para a metodologia da pesquisa e estudo dos gêneros acadêmicos, bem como a inserção de práticas de investigação científica nos conteúdos programáticos das disciplinas em geral.

b) Administração do tempo e do espaço escolar na educação básica, que possibilite o investimento em práticas de pesquisa e publicação dos resultados por meio de gêneros discursivos condizentes e suportes adequados, obviamente respeitado o nível de conhecimento dos alunos.

c) Estímulos aos alunos e professores para participarem de eventos de iniciação científica, como feira de ciências, inovação e tecnologia; congressos; publicação de artigos científicos, resenhas críticas, relatórios, entre outros gêneros que envolvem a pesquisa.

d) Criação de grupos de pesquisa que possibilitem a reflexão, a tomada de decisões e criação de protótipos científicos, tecnológicos e educacionais que atendam à realidade da comunidade escolar e acadêmica.

e) Aparelhamento das escolas com bibliotecas, laboratórios de pesquisa e de informática, além dos insumos e demais recursos necessários ao seu bom funcionamento.

f) Formação de parcerias entre universidades e escolas da educação básica, e ainda entre empresas e escolas, com vistas a promoverem atividades conjuntas voltadas para a formação dos alunos e ainda para proposição de inovações científicas e tecnológicas.

g) Investimento na carreira e na formação dos professores para que eles possam criar e implementar uma cultura de pesquisa no espaço escolar em que atuam.

Por fim, o fomento à pesquisa deve deixar de ser apenas dispositivo legal para se transformar em conhecimento e ação na educação básica e superior. Aprende-se a pesquisar investindo em práticas de pesquisa e na divulgação dos resultados por meio de gêneros específicos, que precisam ser ensinados. Se quisermos que nossos alunos desenvolvam habilidades de pesquisa, é fundamental que os objetos de conhecimento sejam trabalhados a partir de situações concretas que favoreçam práticas de investigação adequadas à sua realidade sócio-histórica. A leitura e a produção de textos acadêmicocientíficos devem ser motivadas, dada sua importância tanto para a materialização e divulgação dos resultados das investigações realizadas, como para que o aluno possa criar uma identidade com o meio acadêmico e participar ativamente das atividades dessa esfera comunicativa.

\section{CONSIDERAÇÕES FINAIS}

Neste artigo, refletimos sobre a necessidade de desenvolvimento de práticas de letramento acadêmico-científico desde a educação básica, com vistas à formação de alunos capazes de estabelecer conexões com o conhecimento acadêmico-científico e a sociedade em que vivem. Arrolamos, na discussão, o referencial teórico acerca dos gêneros discursivos (BAKHTIN, 1997; SWALES, 1990, 2004), com ênfase no 
dialogismo, no caráter sócio-histórico, configuração básica, propósito comunicativo e esfera de atividade. Em seguida, refletimos sobre a importância do investimento em práticas de letramento na educação básica, conforme preconizam os documentos oficiais. Quanto à graduação, relacionamos algumas pesquisas que denunciam o baixo investimento em pesquisa e a dificuldade dos alunos em ler e produzir textos acadêmicos.

Procedemos ao levantamento de dados a partir de um questionário de oito questões abertas, que foram respondidas por um grupo de recém-graduandos no curso de Letras de uma escola da rede federal de ensino. Entre essas perguntas, quatro foram escolhidas para análise. Após o levantamento dos dados, organizamos as informações que contribuíram para responder a nossa pergunta-chave e atingir os objetivos da pesquisa. As respostas sinalizaram pouco conhecimento sobre os gêneros acadêmicos, o baixo nível de aprendizagem na educação básica relacionado à leitura e produção de gêneros acadêmicos e a importância do letramento acadêmico na e para a formação profissional.

A análise evidenciou a importância do investimento em atividades de pesquisa desde a educação básica em atendimento às normas expressas na Base Nacional Comum Curricular - BNCC (BRASIL, 2018). Tais atividades serão mais bem-sucedidas se forem considerados os eventos de letramento, em especial a leitura e produção de gêneros envolvidos nas atividades de investigação científica. Uma formação sólida nesse nível de ensino contribuirá sobremaneira para a continuidade das atividades de pesquisa na graduação, bem como para a identificação e a sensação de pertencimento dos graduandos à comunidade acadêmica.

As considerações ainda destacam, entre outros aspectos, a necessidade de investimento, tanto na educação básica quanto na superior, em recursos humanos e tecnológicos que possibilitem à comunidade escolar promover a organização dos tempos e espaços essenciais à pesquisa; integração entre os diferentes níveis de ensino e ainda entre empresas e escolas, com o propósito de desenvolver atividades voltadas para o fomento da ciência e tecnologia em todos as esferas de atividade humana; e investimento na formação e na carreira dos professores com vistas à criação e implementação de uma cultura de pesquisa nas escolas. Ressaltamos, por fim, que a associação entre pesquisa e ensino configura-se como um indicador do aumento do padrão de qualidade de nossas escolas e torna mais expressiva sua função social na construção de uma sociedade autônoma, científica, tecnológica e culturalmente, e que investe na educação como um pilar para o desenvolvimento econômico e sustentável.

\section{REFERÊNCIAS}

ARANHA, S. The development of a genre-based writing course for graduate students in two fields. In: BAZERMAN, C.; BONINI, A.; FIGUEIREDO, D. (Org.). Genre in a changing world. Colorado: The WAC Clearinghouse and Parlor Press, p. 465-482, 2009.

ARAÚJO, C. M.; BEZERRA, B. G. Letramentos acadêmicos: leitura e escrita de gêneros acadêmicos no primeiro ano do curso de letras. DIÁLOGOS - Revista de Estudos Culturais e da Contemporaneidade, $\mathrm{n}$. 9, maio/jun. 2013.

BAKHTIN, M. Estética da criação verbal. Trad. Maria Ermantina Galvão G. Pereira. São Paulo: Martins Fontes, 1997.

BAZERMAN, C. The life of genre, the life in the classroom. In: W. Bishopand; H. Ostrum (Eds.), Genre and writing. Portsmouth, NH: Boynton/Cook, 1997, p. 19-26. 
BEZERRA, B. G. Gêneros acadêmicos em cursos de especialização: conjunto ou colônia de gêneros? RBLA, Belo Horizonte, v. 12, n. 3, p. 443-461, 2012.

BEZERRA, B. G. Letramentos acadêmicos e construção da identidade: a produção do artigo científico por alunos de graduação. Linguagem em (Dis)curso - LemD, Tubarão, SC, v. 15, n. 1, p. 61-76, jan./abr. 2015.

BIASI-RODRIGUES, B.; ARAÚJO, J. C.; SOUZA, C. S. T. Análise de gêneros na abordagem de Swales: princípios teóricos e metodológicos. In: BIASI-RODRIGUES, B.; ARAÚJO, J. C.; SOUZA, C. S. T. (Org.). Gêneros textuais e comunidades discursivas: um diálogo com John Swales. Belo Horizonte: Autêntica Editora, 2009, p. 17-32. (Coleção Leitura, Escrita e Oralidade).

BRASIL. Ministério da Educação. Base Nacional Comum Curricular. Educação é a base. Brasília: MEC, 2018. Disponível em:

http://basenacionalcomum.mec.gov.br/images/BNCC_EI_EF_110518_versaofinal_site.pdf. Acesso em: 20 out. 2019.

BRASIL. Lei de Diretrizes e Bases da Educação Nacional. Lei no 9394, 20 de dezembro de 1996.

BRONCKART, J. P. Atividade de linguagem, textos e discursos: por um interacionismo sócio-discursivo. Trad. Anna Rachel Machado e Pericles Cunha. São Paulo, Educ, 1999.

FIGUEIREDO, D. C.; BONINI, A. Práticas discursivas e ensino do texto acadêmico: concepções de alunos de mestrado sobre a escrita. Linguagem em (Dis)curso - LemD, Tubarão, v. 6, n. 3, p. 413-446, set./dez. 2006.

FREIRE, P. Pedagogia da autonomia: saberes necessários à prática educativa. Rio de Janeiro: Paz e Terra, 2001.

FREIRE, P. Pedagogia do oprimido. Rio de Janeiro: Paz e Terra, 2005.

GIL, A. C. Como elaborar projetos de pesquisa. São Paulo: Atlas, 2019.

KAY, H.; DUDLEY-EVANS, T. Genre: What teachers think. ELT Journal, v. 52, n. 4, p. 308-314, 1998.

KOCH, I. G. V. A coesão textual. 13. ed. São Paulo: Contexto, 2000.

KOCH, I. G. V. O texto e a construção dos sentidos. 9. ed. São Paulo: Contexto, 2008.

LÜDKE, M.; CRUZ, G. B. Aproximando universidade e escola de educação básica pela pesquisa. Cadernos de Pesquisa, São Paulo, v. 35 n. 125, p. 81-109, maio/ago. 2005.

MARCUSCHI, L. A. Produção textual, análise de gêneros e compreensão. São Paulo: Parábola Editorial, 2008

MOTTA-ROTH, D. A importância do conceito de gêneros discursivos no ensino de redação acadêmica. Intercâmbio, São Paulo, v. VIII, p. 119-128, 1999. Disponível em https://revistas.pucsp.br/index.php/intercambio/article/view/4029/2676. Acesso em: 20 out. 2019.

PIAGET, J. Psicologia e pedagogia. Rio de Janeiro: Forense-Universitária, 1976.

ROJO, R. Gêneros do discurso e gêneros textuais: Questões teóricas e aplicadas. In: MEURER, J. L.; BONINI, A.; MOTTA-ROTH, D. (Org.). Gêneros: teorias, métodos e debates. São Paulo: Parábola Editorial, 2005. p. 184-207.

SWALES, J. M. Genre analysis: English in academic and research settings. Cambridge: Cambridge University Press, 1990.

SWALES, J. M. Research genres: exploration and applications. Cambridge: Cambridge University Press, 2004.

VYGOTSKY, L. A formação social da mente. São Paulo: Martins Fontes, 1984.

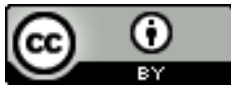

Este texto está licenciado com uma Licença Creative Commons Atribuição 4.0 Internacional. 